\title{
Chronic fatigue syndrome
}

*John Joyce, MB, BCh, MRCPsych, Honorary Senior Registrar, Institute of Psychiatry, King's College School of Medicine and the Institute of Psychiatry, Denmark Hill, London SE5 9RS, England. Simon Wessely, MA, BM, BCh, MSc, MD, MRCP, MRCPsych, Reader in Psychological Medicine, King's College School of Medicine and the Institute of Psychiatry, Denmark Hill, London SE5 9RS, England, Honorary Consultant Psychiatrist, King's College and Maudsley Hospitals.

*Correspondence

\section{What is it?}

Chronic fatigue syndrome (CFS) has been operationally defined as a condition that refers to patients with severe unexplained fatigue and exhaustion, occurring after minimal effort, and accompanied by substantial disability. ${ }^{1}$ Fatigue is both mental and physical, in that patients experience fatigue after physical and mental effort, and experience fatigability of both physical and mental faculties. Currently several sets of research criteria for case definition are in existence: the US (Centre for Disease Control and Prevention), UK (Oxford) and Australian criteria. All include a minimum duration of fatigue of six months, both the US and UK criteria specify fatigue of new or definite onset and the US criteria require a number of concurrent physical symptoms for a diagnosis. (For the 1994 CDC these are at least four of the following: impaired memory or concentration, sore throat, tender cervical or axillary lymph nodes, muscle pain, multijoint pain, new headaches, unrefreshing sleep and post-exertion malaise).

In practice, CFS overlaps with the label of 'myalgic encephalomyelitis' (ME) - a label that is scientifically inappropriate but is widely used to encompass a variety of diseases, illnesses and predicaments. Other terms which refer to an either unproven or as yet unascertained distinct neuropathological process include postviral fatigue syndrome (PVFS) and chronic fatigue immune dysfunction syndrome (CFIDS).

\section{Who gets it?}

Recent population and primary care based studies report prevalences ranging from $0.3 \%$ to $1.5 \% .^{2.3}$ However one study showed only $0.2 \%$ of the population believe that they have $\mathrm{ME} / \mathrm{CFS}^{4}$ raising the interesting question of the difference between prevalence and presentation and what determines it (vide infra). Women are over represented in specialist samples of CFS in nearly all epidemiological surveys. Sex differences in population based studies are considerably more modest with a relative risk of women to men of the order of $1: 3 .^{4}$

\section{Is it new?}

The term ME was coined in 1957 after the notorious outbreak of a paralytic illness among nurses at London's Royal Free Hospital. As epidemics, always of uncertain and heterogenous aetiology disappeared from the scene, the label ME became attached to sporadic cases of fatiguing illnesses. Disillusionment with the term ME meant UK researchers were very willing to adopt the term chronic fatigue syndrome (CFS), an American import first adopted by a meeting of immunologists and infectious disease specialists in Atlanta and used in the ground breaking US Centres for Disease Control and Prevention 1988 operational criteria. ${ }^{6}$ However, there can be little dispute that the condition covered by the term CFS has been around for far longer, and has its origins in the neurasthenia of the end of the 19th century. ${ }^{7}$ The similarities between neurasthenia and CFS, in terms of symptoms, social profiles, presumed aetiologies and treatment, are very striking. ${ }^{8,9}$

\section{Overlap with other syndromes}

Fibromyalgia and irritable bowel syndrome also present with prominent fatigue and share many clinical and demographic features with CFS, generating speculation that they may be all aspects of one generalised disorder. In addition symptoms of hyperventilation have been reported in over $10 \%$ of patients. ${ }^{10}$ Claims have been made for a link between CFS and ill-defined conditions such as multiple chemical sensitivity, food allergy and total allergy syndrome which connection may be accounted for via an underlying predisposition to somatisation..$^{11,12}$

\section{Aetiology}

\section{Viral/immunological}

The aetiology of CFS remains uncertain. Considerable attention has been given to immunological and virological explanations. Some patients show immunological abnormalities, such as increased memory cells or low levels of natural killer cells, but these are inconsistent and non-specific. There is little evidence of an association with clinical disability, and no evidence that they influence outcome. ${ }^{13}$ The role of infection is unclear, but has probably been over estimated. ${ }^{3}$

Patients presenting to specialists usually report that their illness was precipitated by a viral type infection. However, in a large primary care cohort study we were unable to show any role for common viral infections as aetiological factors. ${ }^{14}$ Several early studies suggested that the enterovirus family was implicated in CFS, but later investigations have, with a single exception, ${ }^{15}$ not confirmed these findings. ${ }^{16,17}$ Other possible viral causes including retroviruses and herpes viruses ${ }^{18}$ have been investigated without clear outcome. Viral meningitis is a risk factor for subsequent CFS, but probably more as a nonspecific severe stress than via a direct biological mechanism. ${ }^{19}$ Only Epstein Barr virus (EBV) appears to be associated with a direct post-infectious fatigue syndrome specific to that virus. ${ }^{20}$

\section{Psychiatric contributions}

There are substantial overlaps between CFS and the major psychiatric diagnostic categories. Most patients who fulfil criteria for CFS and are seen in specialist samples also fulfil criteria for psychiatric diagnoses, chiefly depression. ${ }^{21}$ Controlled studies have shown that these rates cannot be explained as a consequence of physical disability. ${ }^{22,23}$ As similar associations are also found in primary care, selection bias 
is also not an explanation..$^{24,25}$ Instead there are three overlapping interpretations of these findings. First, CFS is simply a misdiagnosis of psychiatric disorder. As every study to date shows that there is a substantial minority of subjects who do not fulfil any criteria for psychiatric disorder (assuming one discounts neurasthenia) this cannot be sustained, but is clearly appropriate in some cases.

In every study between one third and one half of cases do not fulfil criteria for any psychiatric disorder. Even within depressed cases, there are phenomenological differences between CFS and major depression. Some of these, such as relative absence of guilt and preservation of self esteem, might be explained on the basis of the external, as opposed to internal, attributions, made by most CFS patients in specialist care. ${ }^{26}$ Second, both CFS and psychiatric disorder are expressions of a single underlying neurobiological process. This will be discussed further. Third, such overlap may be an inevitable consequence of the overlap between the diagnostic criteria for the principal psychiatric disorders and those for CFS.

Most studies and reviews on the subject of CFS and psychiatric disorder have tended to emphasise the role of depressive illness rather than anxiety disorders. However, this is probably unjustified. Anxiety disorders are also common, ${ }^{27}$ whilst current formulations of CFS emphasise the key role played by fearful cognitions in determining avoidance behaviour and disability (vide infra). The neurobiology may also show closer overlaps with anxiety rather than depressive disorders. The emphasis on depression at the expense of anxiety may reflect both the hierarchical nature of psychiatric disorder, the demise of the rich historical tradition of neurocirculatory asthenia, effort syndrome, Soldier's heart and their close associations with anxiety disorders, ${ }^{28,29}$ and the general shift of fashion and diagnostic preference from anxiety to depression. ${ }^{30}$

Quite how one considers neurasthenia is unclear. Neurasthenia, which disappeared from Western diagnostic systems earlier in the century is now back in ICD-10, but clearly as a neurotic disorder. Post-viral fatigue syndrome also appears in ICD-10, with a case definition remarkably similar to that of neurasthenia. This is partly a political solution to current diagnostic controversies, allowing those who follow either psychiatric or organic models to incorporate the diagnosis in their formulations. ${ }^{31}$ Modern epidemiological studies are starting to determine the prevalence of operationally defined neurasthenia, which is common in the community, ${ }^{32}$ and could be diagnosed in virtually everyone who attends a specialist CFS clinic. ${ }^{33}$ Rather than attempting ever more fine tuned distinctions between CFS and neurasthenia a population perspective is likely to conclude that both lie in dimensional space on an axis somewhere between anxiety and depression, ${ }^{34}$ and that both are so closely intertwined that separating them makes little clinical, epidemiological and statistical sense.

\section{Neurobiology}

Interest in possible HPA axis abnormalities in CFS was generated by the similarities between symptoms in Addison's disease (primary adrenal insufficiency) and CFS. Demitrack and colleagues ${ }^{35}$ showed that CFS patients had a low evening plasma cortisol level, and decreased 24 hours urinary free cortisol output, suggestive of mild hypocortisolism. Pituitary responsiveness to $\mathrm{CRH}$ was reduced, while the adrenal cortices were hyper responsive to low doses of administered ACTH. However, at higher doses the adrenal cortisol response was impaired. This was interpreted as evidence of mild hypocortisolism of central origin. Similar findings have been reported in the related condition of fibromyalgia. ${ }^{36}$

Cortisol is closely related to central 5-HT systems - stress induced CRH secretion is partially controlled by 5-HT-la neurones projecting to the hypothalamus. ${ }^{37} \mathrm{We}$ recently studied central neuro 5-HT function in CFS patients without comorbid depression by measuring the prolactin response to the d-fenfluramine. ${ }^{38} \mathrm{CFS}$ patients showed higher 5-HT mediated responses than controls, with lower circulating cortisol levels. Depressed patients showed the opposite. Increased central 5-HT responsiveness was also found in a previous study. ${ }^{39}$

We are still unclear about the importance of these observations. It may be that they reflect the observed differences between CFS patients, characterised by hypersomnia, appetite gain and fatigue, and classic major depression, with insomnia, anorexia and agitation - it is possible the neuroendocrine changes are simply epiphenomena of these functional differences. ${ }^{40}$ The similarity between the preliminary neuroendocrine profiles found in CFS and those observed in disorders closer to anxiety than depression, such as post traumatic stress disorder, is also intriguing. ${ }^{41}$ Some formulations of disability in CFS (vide infra) place greater emphasis on the role of exercise avoidance, fear and conditioned responses rather than simple mood disorder, suggesting that depression per se may be an inadequate explanation of CFS. It also suggests that CFS (in the absence of depression) lies at one end of a spectrum of HPA activity, in which major depression is found at the other.

\section{Neuroimaging}

Four magnetic resonance imaging (MRI) studies of CFS have been published. ${ }^{42}$ Cerebral white matter abnormalities have been reported in some, but not all. The most recent study of subjects with post-viral fatigue recruited in primary care found no increase in MRI abnormalities. ${ }^{43}$ Findings of white matter abnormalities require careful interpretation, since it is a sensitive technique and may reveal 'abnormalities' of little consequence.

Six studies have so far been published using functional neuroimaging techniques such as SPECT in CFS. There are problems in interpreting the results, since most have used inconsistent case definitions, resting scans, poor resolution SPECT scanners and semi-quantitative methods to detect changes in regional cerebral blood flow (RCBF) ${ }^{42}$ Not surprisingly the results are inconsistent. The most widely publicised study found that brainstem perfusion was significantly reduced in CFS subjects compared to controls, with depressed patients showing intermediate values. ${ }^{44}$ However, other groups do not report brainstem perfusion values because of the technical difficulties of imaging this small structure. One must be cautious about the interpretation of this finding. ${ }^{42}$ Even with improved methodologies problems will remain in interpreting SPECT studies, as already occurs in established fields such as schizophrenia research. It is difficult to determine whether any deficit in RCBF in response to the task is the cause or result of the performance deficit.

\section{Possible misconceptions}

Coverage in the popular and peer reviewed literature has been noted to diverge with articles in the popular press tending to favour a model in which one pathogenic agent causes a specific pathological event. ${ }^{45}$ Evidence to support sometimes recommended dietary supplements (vitamins and minerals) ${ }^{46}$ or elimination, avoidance and rotation diets either to exclude additives or combat candida remain anecdotal. ${ }^{47}$ Frequently held fears on the part of patients that a possible trigger agent such as a virus may persist and be a progressive source of pathological damage (as in HIV) can also be assuaged using the available evidence (vide supra). Similar reassurance can 
be given in regard to concerns about primary muscle disorder as there is no confirmation of objective deficits in neuromuscular function. ${ }^{48}$ Formal studies of neuropsychological function show a disorder of effortful cognition rather than any actual deficits in recall ${ }^{49,50}$ again allowing the clinician to reassure the patient that despite distressing symptoms of cognitive dysfunction ongoing deterioration in memory function is unlikely. Notions which have entered public consciousness with remarkable force such that sufferers only belong to a higher social class or are made up of those with driven, high achieving lifestyles are not confirmed in primary care settings, and are likely to be artefacts of selection bias in specialist settings. ${ }^{3}$ The advice that prolonged rest and inactivity is the only approach to treatment can be confidently discounted (see below).

\section{Children}

Research in this area is sparse despite an increasing number of children being reported as having CFS. Its impact on all aspects of development must be severe. There is a growing professional literature on CFS in childhood, but one that has a strong psychosocial flavour. It has been argued that CFS in children is associated with somatisation, ${ }^{51-53}$ depression, ${ }^{53.55}$ and even bipolar disorder. ${ }^{56,57}$ Even if the nature of CFS in children remains unclear, psychological factors are certainly relevant. David Bell, a Harvard paediatrician closely associated with CFS, writes that "there is little doubt that depression occurs in children with CFS... nearly $60 \%$ to $80 \%$ of children with CFS will describe depression among the symptoms", although self harm seems very unusual. No formal treatment studies exist but the only successful reports in the literature generally follow a behavioural package often combined with a family/systems approach..$^{58-64}$

\section{Differential diagnosis}

Although any condition presenting with prominent fatigue enters the differential diagnosis the principal message is that a good psychosocial history and physical examination and basic laboratory tests (full blood count, ESR, electrolytes, liver and thyroid function) is usually sufficient to establish the diagnosis. ${ }^{65}$ Unless physical or laboratory examination reveals significant abnormalities the yield from further sophisticated tests is low, ${ }^{66}$ in contrast to the yield from psychosocial assessments.

\section{Prognosis}

The prognosis for CFS as seen in specialist clinics is of concern. Although improvements do occur, few sufferers return to a symptom and disability free life, at least not over the next three to five years. ${ }^{67-70}$ The predictors of poor outcome are of interest - in general biological variables such as immunological or serological variables are not associated with outcome. In contrast psychological and attributional factors do play a role. An association has been demonstrated between fatigue and psychological distress experienced before the viral infection and later fatigue. Overall the strength of the sufferer's attribution of his or her symptoms to a solely physical cause is the best predictor of poor outcome.

One controversial finding is that in two studies, ${ }^{67,71}$ but not a third, ${ }^{72}$ membership of a self-help group was independently associated with either poor prognosis or poor compliance with treatment. One plausible interpretation is that membership is associated with longer illness duration and greater illness severity. Another is that membership of a self-help group is associated with certain beliefs and illness behaviours, such as symptom reinforcement, anti mental health biases and a belief in the efficacy of rest and avoidance behaviours. Only a randomised trial of group membership would resolve the issue, and as that seems pragmatically impossible, the issue will remain unresolved.

\section{Management}

\section{Pharmacological}

Given the overlap between the symptoms of depression and those of CFS, antidepressants have been regularly proposed for the management of the condition. Until recently the evidence has come only from uncontrolled, open or case studies. ${ }^{73-75}$ Current work on possible impairment in serotonergic pathways (vide supra) is used to justify the use of serotonin re-uptake inhibitors (SSRI) ${ }^{76}$ and early studies were encouraging. ${ }^{77}$ It is therefore surprising that the first placebo controlled trial of an SSRI (fluoxetine) should have been resoundingly negative,$^{78}$ although some indication of this result was given by a negative study of the same drug in fibromyalgia. ${ }^{79}$ The Dutch study showed that fluoxetine was ineffective even in CFS with comorbid depression, a counterintuitive finding. ${ }^{78}$ In contrast another randomised controlled trial of fluoxetine from the UK was positive, although problems were encountered with compliance. ${ }^{71}$

Turning to the older antidepressants, there are some clinical reasons for avoiding drugs with a high sedative or anticholinergic profile, ${ }^{80}$ although we experienced few difficulties using dothiepin combined with CBT. ${ }^{81}$ Given the overlap between the symptoms of CFS and those of atypical depression, and the efficacy of monoamine oxidase inhibitors (MAOIs) in the latter, ${ }^{82}$ a good case can also be made for trying them. A very preliminary observation also suggests some rationale for using moclobemide, a novel reversible MAOI agent. ${ }^{80}$

Despite the negative finding of the Dutch group using fluoxetine, we continue to suggest that antidepressants are indicated for mood disorder, regardless of its origins. A more interesting, and still unresolved, question is the role of antidepressants in those without obvious evidence of affective disorder. Another question is the role of antidepressants in sleep disorder, an extremely common association of CFS, and thought by some to be of aetiological significance. ${ }^{83}$ In conclusion it is impossible at the moment to give any firm guidelines on the use and choice of antidepressants in CFS.

Moving away from antidepressants a number of so called specific treatments have been proposed to deal with the presumed underlying 'cause' of the abnormal fatigability. For example, given that recent formulations of CFS involve abnormal immunity, it was inevitable that immunoglobulins would be tried. One study found in their favour, and one against. Technical aspects of the study, and the problems of side effects and cost have led the editorialists to conclude that immunoglobulin therapy is unjustified in CFS. ${ }^{84,85}$ Less specific treatments are at present extremely popular, in particular evening primrose oil and magnesium, both found efficacious in well publicised clinical trials. However, there is no convincing rationale for their use, and other studies have been less favourable. ${ }^{86}$

\section{Non-pharmacological}

Our group and our colleagues at the University of Oxford have suggested an alternative model for understanding chronic fatigue syndrome. ${ }^{87.89}$ At the heart is the message that whatever triggers CFS may not perpetuate it. For example, an ordinary viral infection may precipitate fatigue which, for the majority of the population, is resolved when a normal recovery is made. However, on rare occasions the presence of perpetuating factors (such as psychosocial stressors, rapid 
day increasing to a maximum of $40 \mathrm{mg}$

dependent upon individual patient

response. Children. Not recommended.

Restrict dosage to lower end of range in

hepatic impairment. Dosage adjustment not necessary in cases of mild/moderate renal impairment. No information available in severe renal impairment (creatinine

clearance $<20 \mathrm{ml} / \mathrm{min}$ )

Contra-indications: Combined use of 5 HT agonists. Hypersensitivity to citalopram. Pregnancy and Lactation: Safety during human pregnancy and lactation has not been established. Use only if potential been established. Use only if potent outweighs possible risk. Precautions: Driving and operating machinery. History of mania. Caution in patients at risk of cardiac arrhythmias. Do not use with or within 14 days of MAO inhibitors: leave a seven day gap before starting MAO inhibitor treatment.

Drug Interactions: MAO inhibitors

(see Precautions) Use lithium and tryptophan with caution. Routine monitoring of lithium levels need not be adjusted. Alcohol is not advised. Adverse Events: Most commonly nausea, sweating, tremor, somnolence and dry mouth.

Overdosage: Symptoms have included somnolence, coma, sinus tachycardia, occasional nodal rhythm, episode of grand mal convulsion, nausea, vomiting, sweating and hyperventilation. No specific antidote. Treatment is symptomatic and supportive. Early gastric lavage suggested.

Legal Category: POM.

Further information available upon request. Product Authorisation holder:

Lundbeck (Ireland) Limited, 4 Burton Hall Park, Sandyford Industrial Estate. Foxrock,

Dublin 18. PA number 776/1/2.

'Cipramil' is a trademark. (C) 1995 Lundbeck (Ireland) Limited.

Date of preparation: January 1996.

References

I. Hyttel J, XXII Nordiske PsykiaterKongres, Reykjavik, II August, 1988 11-21. 2. Richelson E, J Clin Psychiatry 1991: 52:6 (Suppl): 4-10. 3. Rosenberg C et al, Int Clin Psychopharmacol 1994; 9 (Suppl I): 4|-48. 4. Shaw DM et ol, Br ] Psychiatry 1986; 149: 515-517. 5. Data on file (6), Lundbeck 1995. 6. Montgomery SA, Rasmussen JGC, Tanghoj $P_{1}$ Int Clin Psychopharmacol 1993; 8: 181-188. 7. Montgomery SA et al, Int Clin Psychopharmacol 1994: 9 (Suppl 1): $35-40$. 8. Data on file (I), Lundbeck 1995. 9. Bech $P$ and Cialdella P. Int Clin Psychopharmacol 1992; 6 (Suppl 5): 45-54. 10. Gram L.F et al. Ther Drug Monit 1993; I5: 18-24. II. Van Harten J. Clin Pharmacokinet 1993 : 24 (3): 203-220.12. Sindrup SH et al, Ther Drug Monit 1993; 15: 11-17. 13. Lader M et ol, Eur I Clin Pharmaco 1986: 31: | $83-190$.

\section{Now you can lift depression}


Site-specific 'Cipramil' addresses four dimensions of antidepressant therapy

\section{with the body in mind.}

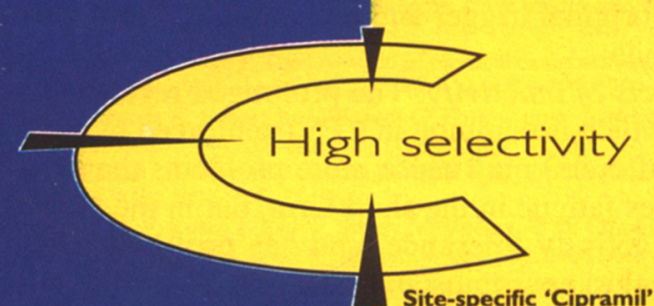

Site-specific 'Cipramil’ offers highly selective inhibition of serotonin (5-HT) reuptake in central synapses (in vitro)'. At the same time, it has a low in vitro affinity for inappropriate receptor sites' which have the potential to cause unwanted effects ${ }^{2}$.
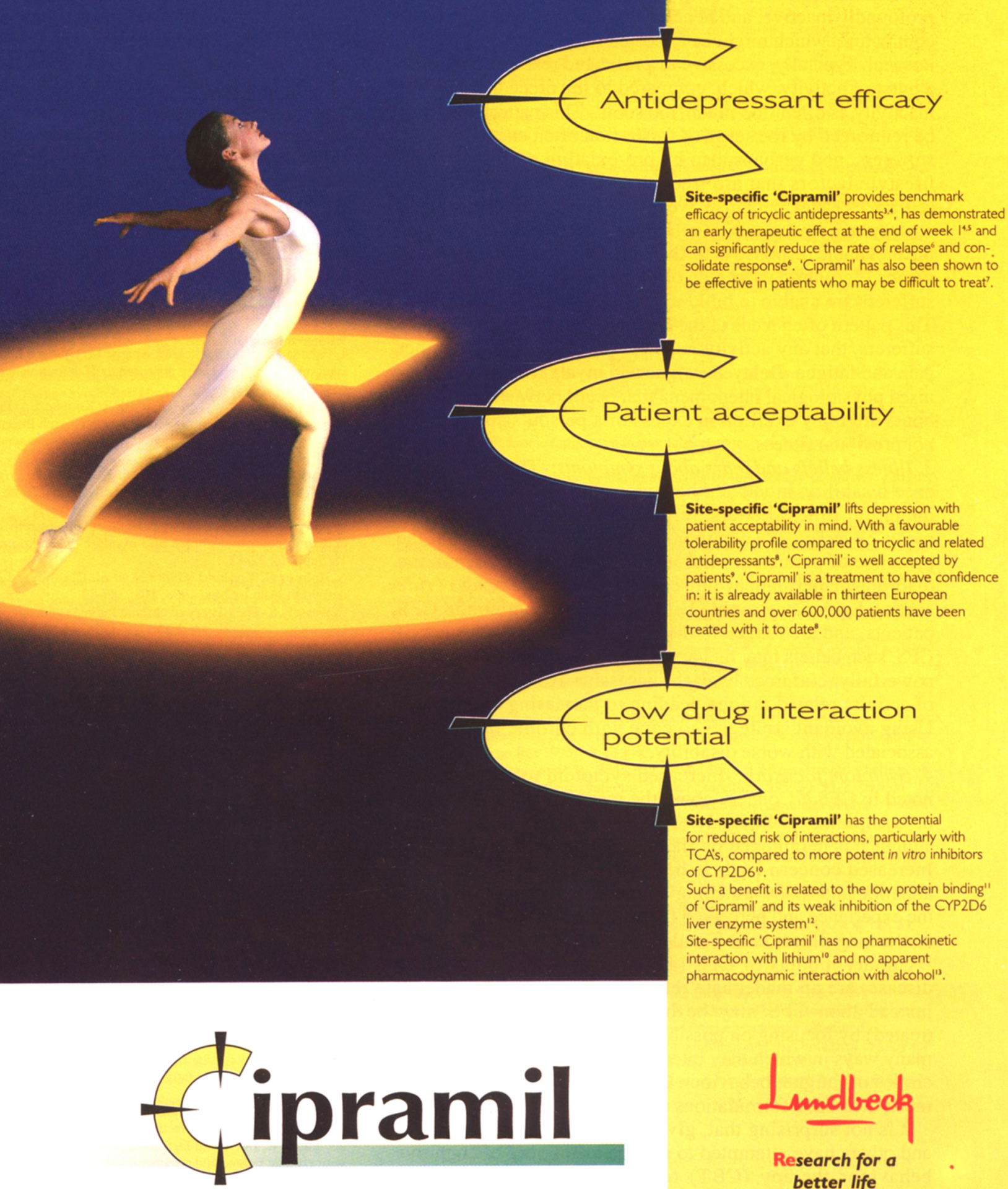

Lindlecth

Research for a better life

\section{Specifically treating depression}


deconditioning, failure to rest adequately or concurrent depression and/or anxiety) may delay or impede recovery. Fatigue then becomes chronic, persisting long after the departure of the original trigger and maintained by new variables. These include:

1. The effects of inactivity: The prolonged rest and extreme inactivity which is common in CFS (reinforced by the advice given to sufferers) may cause more problems than it solves. Rest relieves fatigue in the short term, but in the longer term it reduces activity tolerance, and has profound effects on cardiovascular, neuromuscular and respiratory function. ${ }^{\mathbf{9 0 - 9 2}}$ With the passage of time, more symptoms, and greater fatigue will continue to occur at progressively lower levels of exertion. Inactivity therefore sustains symptoms, and increases sensitivity to them.

2. Inconsistent activity: In practice CFS sufferers are rarely profoundly inactive, and hence complications such as muscle contracture, which might be expected to be common, are very unusual. Typically, excessive or prolonged rest is followed by a burst of activity, which, compared to the preceding level of inactivity, is often 'too much, too soon'. This pattern may also be reinforced by the sense of frustration often encountered in sufferers, and perhaps also by pre-existing personality and lifestyle factors that are frequently found in the specialist setting..$^{88.93}$ Many patients have attempted sudden increases in activity, and find that they culminate in exhaustion, for which the inevitable response is further rest. This 'stop-start' pattern means that while extremes of disability are often avoided, sufferers are unable to build up a sustained level of recovery. This pattern often leads to the characteristic complaint of CFS sufferers, that any activity must be 'paid for' later by further pain and fatigue. Delayed fatigue and myalgia are well recognised physiological phenomena that occur between 24 and 48 hours after any exertion in excess of a person's current (and not previous) fitness.

3. Illness beliefs and fears about symptoms: These can influence disability, mood and behaviour in any illness. In CFS, unhelpful illness beliefs, reinforced by much ill informed media coverage, are common, and relate to beliefs about the presence of persistent viral infection, progressive immune disorder or permanent muscle and/or brain damage (vide supra). Such catastrophic beliefs are both common in CFS patients, and are related to disability. ${ }^{94}$ In the initial stages of CFS, such beliefs may fuel avoidance of activity, and are often powerfully reinforced by each successive aversive experience of activity related fatigue, leading to increasing restrictions. Using avoidant strategies to cope with chronic fatigue was associated with worse disability. ${ }^{95,96}$

4. Symptom focusing: Increased symptom focusing is also noted in CFS. ${ }^{96}$ Concern about the meaning and significance of symptoms (which are often interpreted as 'warning signals') is heightened by the unpredictable nature of CFS. Increased concern leads to heightened awareness, selective attention and 'body watching', which can then intensify both the experience and perceived frequency of symptoms, thereby confirming illness beliefs and reinforcing illness behaviour.

Unitary models of CFS (a single agent causes a single disease) are an inadequate reflection of clinical reality, and instead than CFS may be better understood (and hence treated) by focusing on possible perpetuating factors, and the many ways in which they interact in self perpetuating vicious circles of fatigue, behaviour, beliefs and disability. ${ }^{87.88 .98}$ Like much else, such formulations are not new. ${ }^{98,99}$

It is not surprising that, given these models of illness, we and others have attempted to use the techniques of cognitive behaviour therapy (CBT) to treat CFS. At present two randomised controlled trials have been carried out in this country. In the first 12 sessions of CBT were compared to standard medical care. ${ }^{100}$ Active treatment led to a satisfactory outcome in $73 \%$ of patients, compared to $27 \%$ of those receiving standard care. Improvements continued in those who had received active treatment during follow up. We have compared 12 sessions of CBT with 12 sessions of relaxation therapy as a control for non specific effects of treatment. ${ }^{101}$ Active treatment again led to reductions in fatigue and functional disability, and again improvement continued during follow up.

In contrast an Australian randomised controlled trial comparing six sessions of CBT with both placebo and immunological therapy showed that a benefit of CBT on selfreported measures of function, but these were not maintained on follow-up, the authors concluding that CBT offered no advantages beyond those of regular medical care and followup. ${ }^{102}$ However, we have suggested that an alternative explanation might be that six sessions is inadequate, given the duration of disability, and that the treatment model may have been compromised by the presence of the active immunological therapy. CBT as practised in London and Oxford assumes that whatever may have triggered CFS, ongoing biological agents (such as persistent viral infection or immune dysfunction) are no longer responsible for symptom perpetuation. ${ }^{103}$

CBT can be given as a formal programme, or, more practically, the techniques of CBT can be integrated into existing rehabilitation programmes. Whichever method is chosen, it appears to be a promising method of reducing disability.

\section{References}

1. Fukuda K, Straus S, Hickie I, Sharpe M, Dobbins J, Komaroff A. The chronic fatigue syndrome: a comprehensive approach to its definition and study. Ann Int Med 1994; 121 : 953-59.

2. Bates D, Schmitt W, Lee J, Kornish R, Komaroff A. Prevalence of fatigue and chronic fatigue syndrome in a primary care practice. Arch Intern Med 1993; 153: 2759-65. 3. Wessely $S$. The epidemiology of chronic fatigue syndrome. Epidemiologic Reviews 1995;17: 139-51.

4. Pawlikowska T, Chalder T, Hirsch S, Wallace P, Wright D, Wessely S. A population based study of fatigue and psychological distress. BMJ 1994; 308: 743-46.

5. Briggs $N$, Levine P. A comparative review of systemic and neurological symptomatology in 12 outbreaks collectively described as chronic fatigue syndrome, epidemic neuromyasthenia and myalgic encephalomyelitis. Clin Infect Dis 1994; 18(Suppl 1): 32-42.

6. Holmes G, Kaplan J, Gantz N, et al. Chronic fatigue syndrome: a working case definition. Ann Int Med 1988; 108: 387-89.

7. Wessely S. The History of chronic fatigue syndrome. in Straus S, ed. Chronic fatigue syndrome. New York: Mark Dekker, 1994: 41-82.

8. Wessely S. Old Wine in new bottles: neurasthenia and 'ME'. Psychol Med 1990; 20: 35-53.

9. Abbey S, Garfinkel P. Neurasthenia and chronic fatigue syndrome: the role of culture in the making of a diagnosis. Am J Psych 1991; 148: 1638-46.

10. Saisch S, Deale A, Gardner W, Wessely S. Hyperventilation and chronic fatigue syndrome. Quart J Med 1994; 87: 63-7.

11. Manu P, Matthews D, Lane T. Food intolerance in patients with chronic fatigue. Int J of Eating Disorders 1993; 13: 203-9.

12. Stewart D. The changing face of somatisation. Psychosomatics $1990 ; 31: 153-8$ 13. Swanink C, Vercoulen J, Galama J, et al. Lymphoctye subsets, apoptosis and cytokines in patients with chronic fatigue syndrome. J of Infect Dis 1996; 173: 460-63. 14. Wessely S, Chalder T, Hirsch S, Pawlikowska T, Wallace P, Wright D. Post infectious fatigue: a prospective study in primary care. Lancet 1995; 345: 1333-38.

15. Clements G, McGarry F, Nairn C, Galbraith D. Detection of enterovirus-specific RNA in serum: the relationship to chronic fatigue. J Med Virol 1995; 45: 156-61.

16. Gow J, Behan P, Simpson K, McGarry F, Keir S, Behan P. Studies of enteroviruses in patients with chronic fatigue syndrome. Clin Infect Dis 1994; 18 (Suppl 1): S126-9. 17. Swanink C, Melchers W, van der Meer J, et al. Enteroviruses and the chronic fatigue syndrome. Clin Infect Dis $1994 ; 19: 860-4$

18. Hay J, Jenkins F. Human herpesviruses and chronic fatigue syndrome. in Straus S. ed. Chronic fatigue syndrome. New York: Mark Dekker, 1994: 181-98.

19. Hotopf M, Noah N, Wessely S. Chronic fatigue and minor psychiatric morbidity after viral meningitis: a controlled study. J Neurol Neurosurg Psych 1996; in press.

20. White P, Thomas J, Amess J, Grover S, Kangro H, Clare A. The existence of a fatigue syndrome after glandular fever. Psychol Med 1995; 25: 907-16.

21. David AS. Postviral fatigue syndrome and psychiatry. Br Med Bull 1991; 47: 96688 .

22. Wessely S, Powell R. Fatigue syndromes: a comparison of chronic 'postviral' fatigue with neuromuscular and affective disorder. J Neurol Neurosurg Psychiat 1989; 52: 940-8. 23. Katon W, Buchwald D, Simon G, Russo J, Mease P. Psychiatric illness in patients with chronic fatigue and rheumatoid arthritis. J Gen Intern Med 1991; 6: 277-85.

24. McDonald E, David A, Pelosi A, Mann A. Chronic fatigue in general practice 
attenders. Psychol Med 1993; 23: 987-98.

25. Wessely S, Chalder T, Hirsch S, Wallace P, Wright D. Psychological symptoms, somatic symptoms and psychiatric disorder in chronic fatigue and chronic fatigue syndrome: a prospective study in primary care. Am J Psychiatry; in press.

26. Powell R, Dolan R, Wessely $S$. Attributions and self-esteem in depression and chronic fatigue syndromes. J Psychosom Res 1990; 34: 665-73.

27. Fischler B, Cluydts R, De Gucht V, Kaufman L, DeMeirleir K. Generalised anxiety disorders in chronic fatigue syndrome. Acta Psychiatrica Scandinavica 1996; in press.

28. Paul O. Da Costa's syndrome or neurocirculatory asthenia. Br Heart J 1987; 58: 30615.

29. Fava G, Magelli C, Savron G, et al. Neurocirculatory asthenia: a reassessment using modern psychosomatic criteria. Acta Psychiatrica Scandinavica 1994; 89: 314-19.

30. Young D. Neurasthenia and related problems. Cul Med Psych 1989; 13: 131-8.

31. David A, Wessely S. Chronic fatigue, ME and ICD-10. Lancet 1993; 342: $1247-8$.

32. Merikangas $K$, Angst J. Neurasthenia in a longitudinal cohort study of young adults. Psychol Med 1994; 24: 1013-24.

33. Farmer A, Jones I, Hillier J, Llewelyn M, Borysiewicz L, Smith A. Neurasthenia revisited: ICD-10 and DSM-III-R psychiatric syndromes in chronic fatigue patients and comparison subjects. Brit J Psychiat 1995; 167: 503-6.

34. Goldberg D, Huxley P. Common mental disorders: a bio-social model. London: Tavistock, 1992.

35. Demitrack M, Dale J, Straus S, et al. Evidence for impaired activation of the Hypothalamic-pituitary-adrenal axis in patients with chronic fatigue syndrome. J Clin End Metab 1991; 73: 1224-34

36. Crofford L, Pillemer S, Kalogeras K, et al. Hypothalamic-pituitary-adrenal axis perturbations in patients with fibromyalgia. Arthritis \& Rheumatism 1994; 37: 1583-92. 37. McEwen B. Neuroendocrine interactions. in Bloom F, Kupfer D, eds. Psychopharmacology: the fourth generation of progress. New York: Raven Press, 1995: 705-18.

38. Cleare A, Bearn J, Allain T, et al. Contrasting neuroendocrine responses in depression and chronic fatigue syndrome. J Affect Disord 1995; 35: 283-89.

39. Bakheit A, Behan P, Dinan T, Gray C, O'Keane V. Possible upregulation of hypothalamic 5 -hydroxytryptamine receptors in patients with postviral fatigue syndrome. BMJ 1992; 304: 1010-12.

40. Leese G, Chattington P, Fraser W, Vora J, Edwards R, Williams G. Short-term nightshift working mimics the pituitary-adrenocortical dysfunction of chronic fatigue syndrome. J Clin End Metab; in press.

41. Yehuda R, Giller E, Southwick S, Lowy M, Mason J. Hypothalamic-pituitary-adrenal dysfunction in post-traumatic stress disorder. Biol Psychiat 1991; 30: 1031-48.

42. Cope H, David A. Neuroimaging in chronic fatigue syndrome. J Neurol Neurosurg Psychiat 1996

43. Cope H, Pernet A, Kendall B, David A. Cognitive functioning and magnetic resonance imaging in chronic fatigue. Brit J Psychiat 1995; 167: 86-94.

44. Costa D, Tannock C, Brostoff J. Brainstem perfusion is impaired in patients with myalgic encephalomyelitis/chronic fatigue syndrome. Quart J Med 1995; 88: 767-73.

45. MacLean G, Wessely S. Professional and popular representations of chronic fatigue syndrome. BMJ 1994; 308: 776-77.

46. Martin R, Ogston S, Evans J. Effects of vitamin and mineral supplementation on symptoms associated with chronic fatigue syndrome with Coxsackie $B$ antibodies. J Nutr Med 1994; 4: 11-23

47. Morris D, Stare F. Unproven diet therapies in the treatment of chronic fatigue syndrome. Arch Fam Med 1993; 2: 181-86.

48. Edwards R, Gibson X, Clague J, Helliwell T. Muscle physiology and histopathology in chronic fatigue syndrome. in Kleinman A, Straus S, eds. Chronic fatigue syndrome. Chichester: John Wiley, 1993: 101-31.

49. Wearden A, Appleby $L$. Research on cognitive complaints and cognitive functioning in patients with chronic fatigue syndrome (CFS): what conclusions can we draw? J Psychosom Res; in press.

50. Moss-Morris R, Petrie K, Large R, Kydd R. Neuropsychological deficits in chronic fatigue syndrome: artifact or reality? J Neurol Neurosurg Psychiat 1996.

51. Garralda M. Severe chronic fatigue syndrome in childhood; a discussion of psychopathological mechanisms. Eur J Child Adol Psych 1992; 1: 111-18

52. Baetz-Greenwalt B, Jensen U, Lee A, Saracusa C, Goldfarb J. Chronic fatigue syndrome (CFS) in children and adolescents; a somatoform disorder often complicated by treatable organic disease. Clin Infect Dis 1993; 17:571.

53. Carter B, Edwards J, Kronenberger W, Michalczyk L, Marshall G. Case control study of chronic fatigue in pediatric patients. Pediatrics 1995; 95: 179-86.

54. Smith M, Mitchell J, Corey L, McCauley E, Glover D, Tenover F. Chronic fatigue in adolescents. Pediatrics 1991; 88: 195-201.

55. Walford G, McCNelson W, McCluskey D. Fatigue, depression and social adjustment in children with chronic fatigue syndrome. Arch Dis Child 1993; 68: 384-8.

56. Sharpe M, Johnson B, McCann J. Mania and recovery from chronic fatigue syndrome. J R Soc Med 1991; 84: 51-2.

57. Giannopoulou J, Marriott $S$. Chronic fatigue syndrome or affective disorder? Implications of the diagnosis on management. Eur J Child Adol Psych 1994; 3: 97- 100. 58. Wachsmuth J, MacMillan H. Effective treatment for an adolescent with chronic fatigue syndrome. Clin Pediatrics 1991; 30: 488-90.

59. Rikard-Bell C, Waters B. Psychosocial management of chronic fatigue syndrome in adolescence. Aus NZ J Psych 1992; 26: 64-72.

60. Vereker M. Chronic fatigue syndrome: a joint paediatric-psychiatric approach. Arch Dis Child 1992; 1992: 550-55.

61. Cox D, Findley L. Chronic fatigue syndrome in adolescence. Br J Hosp Med 1994; 51: 614

62. Pipe R, Wait M. Family therapy in the treatment of chronic fatigue syndrome in adolescence. ACPP Rev and Newsletter 1995; 17: 9-16.

63. Graham H. Family interventions in general practice: a case of chronic fatigue. J Fam
Ther 1990; 13: 225-30.

64. Feder H, Dworkin P, Orkin C. Outcome of 48 pediatric patients with chronic fatigue; a clinical experience. Arch Fam Med 1994; 3: 1049-55.

65. Kroenke K, Wood D, Mangelsdorff D, Meier N, Powell J. Chronic fatigue in primary care: prevalence, patient characteristics and outcome. J Am Med Assoc 1988; 260: 92934.

66. Lane T, Matthews D, Manu P. The low yield of physical examinations and laboratory investigations of patients with chronic fatigue. Am J Med Sci 1990; 299: 313-18.

67. Sharpe M, Hawton K, Seagroatt V, Pasvol G. Follow up of patients with fatigue presenting to an infectious diseases clinic. BMJ 1992; 302:347-52.

68. Wilson A, Hickie I, Lloyd A, et al. Longitudinal study of the outcome of chronic fatigue syndrome. BMJ 1994; 308: 756-60.

69. Clark M, Katon W, Russo J, Kith P, Sintay M, Buchwald D. Chronic fatigue; risk factors for symptom persistence in a 2.5-year follow up study. Am J Med 1995; 98 : 187 95.

70. Vercoulen J, Swanink C, Fennis J, Galama J, van der Meer J, Bleijenberg G. Prognosis in chronic fatigue syndrome (CFS): a prospective study. J Neurol Neurosurg Psychiat 1996.

71. Wearden A, Morriss R, Mullis R, et al. A double-blind, placebo controlled treatment trial of fluoxetine and a graded exercise programme for chronic fatigue syndrome. submitted.

72. Bonner D, Butler S, Chalder T, Ron M, Wessely S. A follow up study of chronic fatigue syndrome. J Neurol Neurosurg Psychiat 1994; 57: 617-21.

73. Lynch S, Seth R, Montgomery S. Antidepressant therapy in the chronic fatigue syndrome. Br J of Gen Prac 1991; $41:$ 339-42.

74. Goodnick P, Sandoval R. Psychotropic treatment of chronic fatigue syndrome and related disorders. J Clin Psych 1993; 54: 13-20.

75. Gracious B, Wisner K. Nortriptyline in chronic fatigue syndrome; a double blind, placebo controlled single case study. Biol Psychiat 1991; 30: 405-08.

76. Lane R. Aetiology, diagnosis and treatment of chronic fatigue syndrome. J Serotonin Res 1994; 1: 47-60.

77. Behan P, Hannifah H. 5-HT re-uptake inhibitors in CFS. Rivista di Immunologia ed Immunofarmacologia 1995; 15: 66-9.

78. Vercoulen J, Swanink C, Zitman F, et al. Fluoxetine in chronic fatigue syndrome; a randomised, double-blind, placebo-controlled study. Lancet 1996; in press.

79. Wolfe F, Cathey M, Hawley D. A double-blind placebo controlled trial of fluoxetine in fibromyalgia. Scan J Rheumatology 1994; 23: 255-59.

80. Wilson A, Hickie I, Lloyd A, Wakefield D. The treatment of chronic fatigue syndrome; science and speculation. Am J Med 1994; 96: 544-49.

81. Butler S, Chalder T, Ron M, Wessely S. Cognitive behaviour therapy in chronic fatigue syndrome. J Neurol Neurosurg Psychiat 1991; 54: 153-58.

82. Liebowitz M, Quitkin F, Stewart J, et al. Antidepressant specificity in atypical depression. Arch Gen Psychiat 1988; 45: 129-37.

83. Morriss R, Sharpe M, Sharpley A, Cowen P. Hawton K, Morris J. Abnormalities of sleep in patients with the chronic fatigue syndrome. BMJ 1993; 306: 1161-64.

84. Straus S. Introvenous immunoglobulin treatment for the chronic fatigue syndrome. Am J Med 1991; 89: 551-53.

85. Anonymous. Chronic fatigue syndrome: false avenues and dead ends. Lancet 1991; 337: 331-32.

86. McCluskey D. Pharmacological approaches to the therapy of chronic fatigue syndrome. in Kleinman A, Straus S, eds. Chronic fatigue syndrome. Chichester: John Wiley, 1993: 280-97.

87. Wessely S, Butler S. Chalder T, David A. The cognitive behavioural management of the postviral fatigue syndrome. in Jenkins R, Mowbray J, eds. Postviral fatigue syndrome. Chichester: John Wiley, 1991: 305-34.

88. Surawy C, Hackmann A, Hawton K, Sharpe M. Chronic fatigue syndrome: a cognitive approach. Behav Res Ther 1995; 33: 535-44.

89. Sharpe M. Chronic fatigue syndrome. Psychiatric Clinics of North America; in press. 90. Asher R. The dangers of going to bed. BMJ 1947; iv: 966-68.

91. Greenleaf J, Kozlowski S. Physiological consequences of reduced physical activity during bed rest. Exercise and Sport Sciences Rev 1982; 10: 84-119.

92. Sharpe M, Bass C. Pathophysiological mechanisms in somatisation. Int Rev Psych $1992 ; 4: 81-97$.

93. Van Houdenhove B, Onghena P, Neerinckx E, Hellin J. Does high 'action-proneness' make people more vulnerable to chronic fatigue syndrome? A controlled psychometric study. J Psychosom Res 1995; 39: 633-40.

94. Petrie K, Moss-Morris R, Weinman J. The impact of catastrophic beliefs on functioning in chronic fatigue syndrome. J Psychosom Res 1995; 39: 31-7.

95. Antoni M, Brickman A, Lutgendorf S, et al. Psychosocial correlates of illness burden in chronic fatigue syndrome. Clin Infect Dis 1994; 18(Suppl 1): S73-8.

96. Ray C, Jeffries S, Weir W. Coping with chronic fatigue syndrome: illness responses and their relationship with fatigue, functional impairment and emotional status. Psychol Med 1995; 25: 937-45.

97. Sharpe M, Chalder T. Management of the Chronic fatigue syndrome. in Illis L, ed. Neurological Rehabilitation. Oxford: Blackwell, 1994: 282-94.

98. Waterman G. The treatment of fatigue states. J Abnorm Psychol 1909; 4: 128-39. 99. Hurry J. The vicious circles of neurasthenia and their treatment. London: Churchill, 1914.

100. Sharpe M, Hawton K, Simkin S, et al. Cognitive behaviour therapy for chronic fatigue syndrome; a randomised controlled trial. BMJ 1996; 312: 22-6.

101. Deale A, Chalder T, Marks I, Wessely S. A randomised controlled trial of cognitive behaviour versus relaxation therapy for chronic fatigue syndrome. submitted.

102. Lloyd A, Hickie I, Brockman A, et al. Immunologic and psychological therapy for patients with chronic fatigue syndrome. Am J Med 1993; 94: 197-203.

103. Chalder T, Deale A, Wessely $S$, et al. Cognitive behavior therapy for chronic fatigue syndrome. Am J Med 1995; 98; 419-22. 